\title{
Dissection of the Cellular and Molecular Events that Position Cerebellar Purkinje Cells: A Study of the math1 Null-Mutant Mouse
}

\author{
Patricia Jensen, ${ }^{1}$ Huda Y. Zoghbi, ${ }^{2}$ and Dan Goldowitz ${ }^{1}$ \\ 1 University of Tennessee Health Science Center, Memphis, Tennessee 38163, and ${ }^{2 H}$ Howard Hughes Medical Institute, \\ Baylor College of Medicine, Houston, Texas 77030
}

Granule cell precursors in the external germinal layer (EGL) of the cerebellum have been proposed to be a major player in the migration and positioning of Purkinje cells through the expression of the Netrin-like receptor Unc5h3 and the extracellular matrix molecule Reelin. To explore the role of the EGL on these processes, we made use of the math1 null-mutant mouse in which the EGL does not form. In the absence of the EGL, we find three populations of ectopic Purkinje cells. First, we find $1 \%$ of all Purkinje cells in a supracerebellar position at the dorsal midline. Second, we find $7 \%$ of all Purkinje cells in the inferior colliculus, similar to what is seen in the Unc5h3 mutant. Our finding that Unc5h3 expression is not disrupted in these cells supports the proposed role of EGL granule cell precursors

A fundamental goal in developmental neurobiology is to determine the controlling elements that guide the migration of neurons from their site of genesis to their normal position in the mature nervous system. In the cerebellum, the migratory path of Purkinje cells, from the ventricular zone (VZ) to their final position in the Purkinje cell layer (PCL) in the cerebellar cortex, has been well documented (Miale and Sidman, 1961; Yuasa et al., 1991; Altman and Bayer, 1997). However, the molecular mechanisms underlying their migration and positioning are just beginning to be discovered. Through the study of neurological mutant mice, several molecules involved in this process have been identified (D'Arcangelo et al., 1995; Ohshima et al., 1996; Ackerman et al., 1997; Howell et al., 1997; Sheldon et al., 1997; Trommsdorff et al., 1999). One such molecule is the extracellular matrix molecule Reelin (D'Arcangelo et al., 1995).

In the homozygous reeler mutant mouse $(r l / r l)$, which contains a mutation in the gene encoding Reelin, $\sim 95 \%$ of the total Purkinje cell population is ectopic, deep to the cerebellar cortex (Heckroth et al., 1989). Previous reports have indicated that Reelin signaling from the external germinal layer (EGL) is essential for the migration of Purkinje cells (Miyata et al., 1997; Curran and D'Arcangelo, 1998; D’Arcangelo and Curran, 1998; Rice and Curran, 1999). However, the EGL is not the sole source of Reelin. Reelin is also expressed in the cells of the nuclear transitory zone (NTZ), which will form the cerebellar nuclei

Received June 19, 2002; revised June 19, 2002; accepted July 11, 2002.

This research was supported by a University of Tennessee Health Science Center, Center for Neuroscience Fellowship (P.J.) and by grants from the Human Frontiers Science Program (D.G.) and Howard Hughes Medical Institute (H.Y.Z.). We thank Dr. Huaitao Yang and Richard Cushing for technical assistance, and Dr. Chris Meade for confocal imaging.

Correspondence should be addressed to Dr. Dan Goldowitz, Department of Anatomy and Neurobiology, University of Tennessee Health Science Center, 855 Monroe Avenue, Memphis, TN 38163. E-mail: dgold@nb.utmem.edu.

Copyright (C) 2002 Society for Neuroscience $0270-6474 / 02 / 228110-07 \$ 15.00 / 0$ in establishing the anterior cerebellar boundary through the expression of Unc5h3. Third, we find $20 \%$ of all Purkinje cells positioned deep to the cerebellar cortex as seen in the reeler mutant. However, unlike the reeler mutant, where $5 \%$ of the Purkinje cells migrate successfully, we find that in the math1 null that $72 \%$ of the Purkinje cells migrate successfully. This finding demonstrates that Purkinje cell migration is not solely dependent on Reelin signaling from the EGL and is likely caused by Reelin signals emanating from the nuclear transitory zone or the ventricular zone, or both.

Key words: Math1; Reelin; Disabled-1; Unc5h3; migration; EGL; granule cell

(Altman and Bayer, 1997), and the VZ (D'Arcangelo et al., 1995; Miyata et al., 1996; Schiffmann et al., 1997; Rice et al., 1998).

To determine the role of these sources of Reelin and to examine the role of the EGL in Purkinje cell positioning, we made use of the math1 null-mutant mouse. math1 codes for a basic helix-loop-helix transcription factor (Akazawa et al., 1995) that is the earliest known marker of granule cell development. In the math1 null mutant, cells of the EGL fail to form (Ben-Arie et al., 1997). The direct effect of the mutation in the cerebellum is restricted to the forming EGL (Ben-Arie et al., 1997), making it an excellent model system to dissect the influence of the EGL on Purkinje cell migration.

In this study we find that a large percentage of Purkinje cells migrate successfully in the math1 null cerebellum. Furthermore, Reelin expression is normal in the NTZ and VZ of the mutant cerebellum. Thus, we demonstrate for the first time that a majority of Purkinje cells can migrate in the absence of an EGLderived Reelin signal. A minority of Purkinje cells, however, are ectopic in the math1 null cerebellum. These cells have increased levels of Disabled-1, suggesting that they are dependent on EGLderived Reelin signal for successful migration.

\section{MATERIALS AND METHODS}

Animals and determination of genotype. Heterozygous math1 mice $\left(\right.$ math $\left.1^{\beta-G a l /+}\right)$, which contain a $\beta$-galactosidase $(\beta$-gal) reporter gene in place of the math1 open reading frame (originally obtained from Dr. Huda Y. Zoghbi, Baylor College of Medicine, Houston, TX) (Bermingham et al., 1999), and reeler mice (originally obtained from the Jackson Laboratory, Bar Harbor, ME) were maintained at the University of Tennessee Health Science Center animal care facility. Mice were kept on a 14-10 hr light/dark cycle with food and water ad libitum. All of the mice were treated in accordance with The Society for Neuroscience policy on the use of animals in research.

Because math $1^{\beta-G a l / \beta-G a l}$ mice are neonatal lethal, all math $1^{\beta-G a l / \beta-G a l}$ and math $1^{+/+}$mice used in this study were generated from matings between math $1^{\beta-G a l /+}$ breeding pairs. Reeler mice were generated from matings 
between heterozygous $(+/ r l)$ males and either $+/ r l$ or homozygous $(r l / r l)$ females. Females were examined each morning for the presence of a vaginal plug. Once a plug was detected, the female was removed from the male, and noon of that day was designated as embryonic day (E) 0.5. Embryos were collected on E13.5, 15.5, 17.5, and the day of birth (P0).

To determine genotype, DNA was isolated from either the tail or yolk sac. The math1 genotype was determined by PCR using the following primers: math1-forward 5'-TAACAGCGATGATGGCAC-3', math1reverse 5'-CTAACAACGATCACCACAGAC-3', lacZ-forward 5' TACCACAGCGGATGGTTCGG-3', and lacZ-reverse 5'-GTGGTGGTTATGCCGATCGC-3'. The PCR reaction was performed in a total volume of $20 \mu \mathrm{l}$ and included an initial denaturation at $94^{\circ} \mathrm{C}$ for $3 \mathrm{~min}$, followed by 30 cycles of $94^{\circ} \mathrm{C}$ for $30 \mathrm{sec}, 55^{\circ} \mathrm{C}$ for $45 \mathrm{sec}$, and $72^{\circ} \mathrm{C}$ for 60 sec, and a final elongation step of $72^{\circ} \mathrm{C}$ for $6 \mathrm{~min}$. Reelin genotype was determined by PCR protocol according to D'Arcangelo et al. (1996).

Tissue preparation. Mice E17.5 or older were anesthetized with Avertin and transcardially perfused with a $0.1 \mathrm{M}$ PBS solution, $\mathrm{pH} 7.3$, followed by fixation with either $4 \%$ paraformaldehyde or a $3: 1$ solution of $95 \%$ ethanol and acetic acid (EtOH/AA). Mice younger than E17.5 were immersion fixed in either $4 \%$ paraformaldehyde or $\mathrm{EtOH} / \mathrm{AA} ; 4 \%$ paraformaldehyde fixed tissue was rinsed with PBS and cryoprotected overnight in a solution of $30 \%$ sucrose in PBS. Tissue was embedded in tissue-freezing medium (TBS, Triangle Biomedical Sciences, Durham, NC), and $20 \mu \mathrm{m}$ sagittal cryosections were mounted on Superfrost Plus slides (Fisher Scientific, Pittsburgh, PA). EtOH/AA-fixed tissue was placed in $70 \%$ ethanol overnight, followed by dehydration in a series of ethanols and clearing in xylenes. Tissue was embedded in paraffin, and 6 $\mu \mathrm{m}$ sagittal sections were mounted on Superfrost Plus slides.

Immunohistochemistry. For each time-point and genotype, adjacent paraffin sections were processed for immunohistochemistry with antibodies against Calbindin (anti-Calbindin D28K 1:500; Chemicon), Disabled-1 (anti-B3 1:300; gift from Brian Howell), Reelin (G10 1:500; gift from Andre Goffinet), or Nestin (anti-Rat401 1:4; Developmental Studies Hybridoma Bank). Slides were cleared in xylenes and rehydrated with graded ethanols. Slides were then rinsed in PBS containing $0.3 \%$ Triton X-100 (PBS/T) and blocked with 5\% normal goat serum, and adjacent sections were incubated overnight at room temperature. Slides were rinsed with $\mathrm{PBS} / \mathrm{T}$ and incubated with a biotinylated secondary antibody (1:200) for $30 \mathrm{~min}$ at room temperature. Immunoreactivity was detected with diaminobenzidine using the ABC Elite kit according to the manufacturer's instructions (Vector Laboratories, Burlingame, CA). For Reelin immunohistochemistry, an additional antigen retrieval protocol (Jiao et al., 1999) was included before incubation with G10 antibody.

Purkinje cell counts. $\mathrm{P} 0$ math $1^{\beta-G a l / \beta-G a l}(n=3)$ and math $1^{+/+}(n=3)$ cerebella, immunostained for Calbindin and sectioned in the sagittal plane, were quantitatively analyzed for Purkinje cell number. Using $100 \times$ oil immersion, the number of Purkinje cells was determined for every fortieth, $6-\mu \mathrm{m}$-thick section, starting at the midline for one-half of the cerebellum. The criterion for counting was the presence of a nucleus in a Calbindin immunopositive cell. The total number of Purkinje cells for one side of the cerebellum was determined using the Abercrombie correction factor (Abercrombie, 1946). The same quantitative procedures were used for calculating ectopic Purkinje cells in the intracerebellar, supracerebellar, and inferior collicular regions.

Birth-dating analysis. For Purkinje cell birth-dating analysis, pregnant dams were injected with two doses of bromodeoxyuridine (BrdU), 50 $\mu \mathrm{g} / \mathrm{g}$ body weight, at gestational ages E11.0 and 11.5 or E12.5 and 13.0. Embryos were collected at P0 and perfusion fixed with EtOH/AA. Tissue was processed for paraffin embedding and sectioned as described above. Sections were cleared in xylenes, rehydrated with graded ethanols, and rinsed in $\mathrm{dH}_{2} \mathrm{O}$. After a rinse with $\mathrm{PBS} / \mathrm{T}$, sections were incubated with anti-Calbindin (1:500) overnight at room temperature. Slides were again rinsed with $\mathrm{PBS} / \mathrm{T}$ and incubated with Alexa Fluor 488-conjugated goat anti-rabbit secondary antibody (Molecular Probes, Eugene, OR) for $2 \mathrm{hr}$ at room temperature. After three 10 min rinses with PBS, slides were fixed in $\mathrm{EtOH} / \mathrm{AA}$ for $15 \mathrm{~min}$ at room temperature. After slides were rinsed in graded ethanols and $\mathrm{dH}_{2} \mathrm{O}$, they were pretreated with $1 \mathrm{~N} \mathrm{HCl}$ at $37^{\circ} \mathrm{C}$ for $30 \mathrm{~min}$. Slides were rinsed with $\mathrm{PBS} / \mathrm{T}$ and incubated with antibodies against BrdU (anti-G4G3 1:4; Developmental Studies Hybridoma Bank) overnight at room temperature. After three, $10 \mathrm{~min}$ rinses with PBS/T, slides were incubated with Alexa Fluor 594-conjugated goat anti-mouse secondary antibody (Molecular Probes) for $2 \mathrm{hr}$ at room temperature. After thorough rinsing, slides were coverslipped with a 2:1 $\mathrm{PBS} /$ glycerol solution.

In situ hybridization. RNA in situ hybridization was performed using riboprobes generated from a plasmid containing Reelin nucleotides 5818-5973 (gift from Tom Curran, St. Jude Children's Research Hospital, Memphis, TN) and a plasmid containing 582 bp of the coding region of Un5h3 (gift from Sue Ackerman, The Jackson Laboratory, Bar Harbor, ME). Riboprobes were labeled with $\left[{ }^{35}\right.$ S]UTP- $\alpha$ S (Amersham Biosciences, Piscataway, NJ) by in vitro transcription according to the manufacturer's instructions (Promega, Madison, WI). E13.5 and P0 cryosections were fixed with $4 \%$ paraformaldehyde followed by pretreatment with $0.25 \%$ acetic anhydride and $0.1 \mathrm{M}$ triethanolamine. Slides were rinsed with $0.2 \times \mathrm{SSC}$ and dehydrated with graded alcohols. Sections were prehybridized for $2 \mathrm{hr}$ at room temperature followed by hybridization with riboprobes at $50^{\circ} \mathrm{C}$ overnight. Sections were rinsed with $2 \times, 1 \times$, and $0.5 \times \mathrm{SSC}$ and digested in $20 \mu \mathrm{g} / \mathrm{ml}$ RNase A (Sigma, St. Louis, MO). Sections were washed in $1 \times$ RNase buffer, $2 \times, 1 \times$, and $0.5 \times \mathrm{SSC}$ at room temperature, and in $0.1 \times \mathrm{SSC}$ overnight at $45^{\circ} \mathrm{C}$. Sections were dehydrated with graded alcohols and exposed to Biomax MR film (Kodak, Rochester, NY) for $3 \mathrm{~d}$ at $-80^{\circ} \mathrm{C}$. Slides were dipped in Kodak NTB-2 emulsion and exposed at $4^{\circ} \mathrm{C}$ for 2 weeks. Slides were developed with Kodak D-19 developer and counterstained with cresyl violet.

\section{RESULTS}

\section{Purkinje cell positioning in the math1 null cerebellum}

In the cerebellum, the primary target of the math1 null mutation is the cells of the rhombic lip resulting in the failed formation of the EGL (Ben-Arie et al., 1997). However, initial analysis of the E18.5 mutant also revealed Purkinje cell ectopia (Ben-Arie et al., 1997), despite the lack of Math1 expression in these cells (Akazawa et al., 1995; Helms and Johnson, 1998). This indirect effect of the math1 null mutation on Purkinje cells suggests the importance of the EGL in Purkinje cell development. To examine the influence of the EGL on Purkinje cells, we performed a detailed analysis of Purkinje cell positioning in the math1 null cerebellum during the time of Purkinje cell migration between E13 and P0. Using antibodies against the Purkinje cell markers Calbindin and Disabled-1, we compared Purkinje cell placement in $m a t h 1^{\beta-G a l / \beta-G a l}$ and math $^{+/+}$cerebella at E13.5, 15.5, 17.5, and P0.

At E13.5 in the math $1^{\beta-G a l / \beta-G a l}$ and math $1^{+/+}$cerebellum, Purkinje cells were aligned in a radial manner migrating outward from the VZ. By E15.5 there were increased cohorts of migrating Purkinje cells present in both the math $1^{\beta-G a l / \beta-G a l}$ and wild-type cerebellum, and at the primitive cortex a Purkinje cell plate (PCP) had begun to form. At these two time points, there were no obvious differences in Purkinje cell placement between the two genotypes. In addition, Nestin immunohistochemistry, used to highlight radial glia, revealed no difference in glial morphology between the mutant and wild-type cerebellum (data not shown).

At E17.5, there were notable differences in Purkinje cell positioning between the two genotypes. In the wild-type cerebellum, the PCP was well defined, and initial fissure formation was evident dividing the Purkinje cells into loosely arranged clusters (Fig. $1 D-F$ ). In the math $1^{\beta-G a l / \beta-G a l}$ cerebellum, the PCP was not as well defined as in the wild-type cerebellum, and no fissure formation was evident (Fig. $1 A-C$ ). In addition, in the anterior region of the cerebellum, Purkinje cells were observed migrating into the mesencephalon (Fig. 1C), and in some cases, Purkinje cells had migrated dorsally past the pial surface of the cerebellum at the midline (Fig. 1A, inset).

By P0, initial foliation had occurred in the wild-type cerebellum, and with the exception of a few Purkinje cells still migrating toward the anterior portion of the cerebellar cortex, almost all of the Purkinje cells reached the PCP (Fig. $1 J-L$ ). In the P0 math ${ }^{\beta-G a l / \beta-G a l}$ cerebellum, initial fissure formation was evident, but no foliation had occurred (Fig. $1 G-I$ ). In addition, the PCP was well defined by the presence of large clusters of Purkinje cells (Fig. $1 G-I$ ). Despite the increase in normally placed Purkinje 
Figure 1. Purkinje cell positioning in the math $^{\beta-G a l / \beta-G a l}$ cerebellum. Sagittal view of medial to lateral sections of an E17.5 math $1^{\beta-G a l / \beta-G a l}(A-C), \quad$ E17.5 math $1^{+/+}(D-F), \quad$ P0 math $1^{\beta-G a l / \beta-G a l}$ $(G-I)$, and $\mathrm{P} 0$ math $^{+/+}(J-L)$ cerebellum immunostained for the Purkinje cell marker Calbindin and counterstained with cresyl violet. Three ectopic populations of Purkinje cells can be seen in the math $^{\beta-\text { Gal } / \beta-\text { Gal }}$ cerebellum that are not present in the wild-type cerebellum. At the midline $(A, G$, and inset) Purkinje cells are found in a supracerebellar position streaming through the dorsal aspect (asterisk) of the cerebellum. In more lateral sections $(C, H, I)$, Purkinje cells are found migrating into the inferior colliculus (double arrows). At the midline $(G)$ and mid-hemisphere $(I)$ of the P0 math $1^{\beta-G a l / \beta-G a l}$ cerebellum, ectopic Purkinje cells $(E)$ are in clusters deep to the PCP $(P)$. In all sections, at P0 $(G-I)$ numerous Purkinje cells are also found in their proper position at the PCP. Scale bar (shown in $L$ ): $A-L, 200$ $\mu \mathrm{m} ; A, G$, inset, $70 \mu \mathrm{m}$.
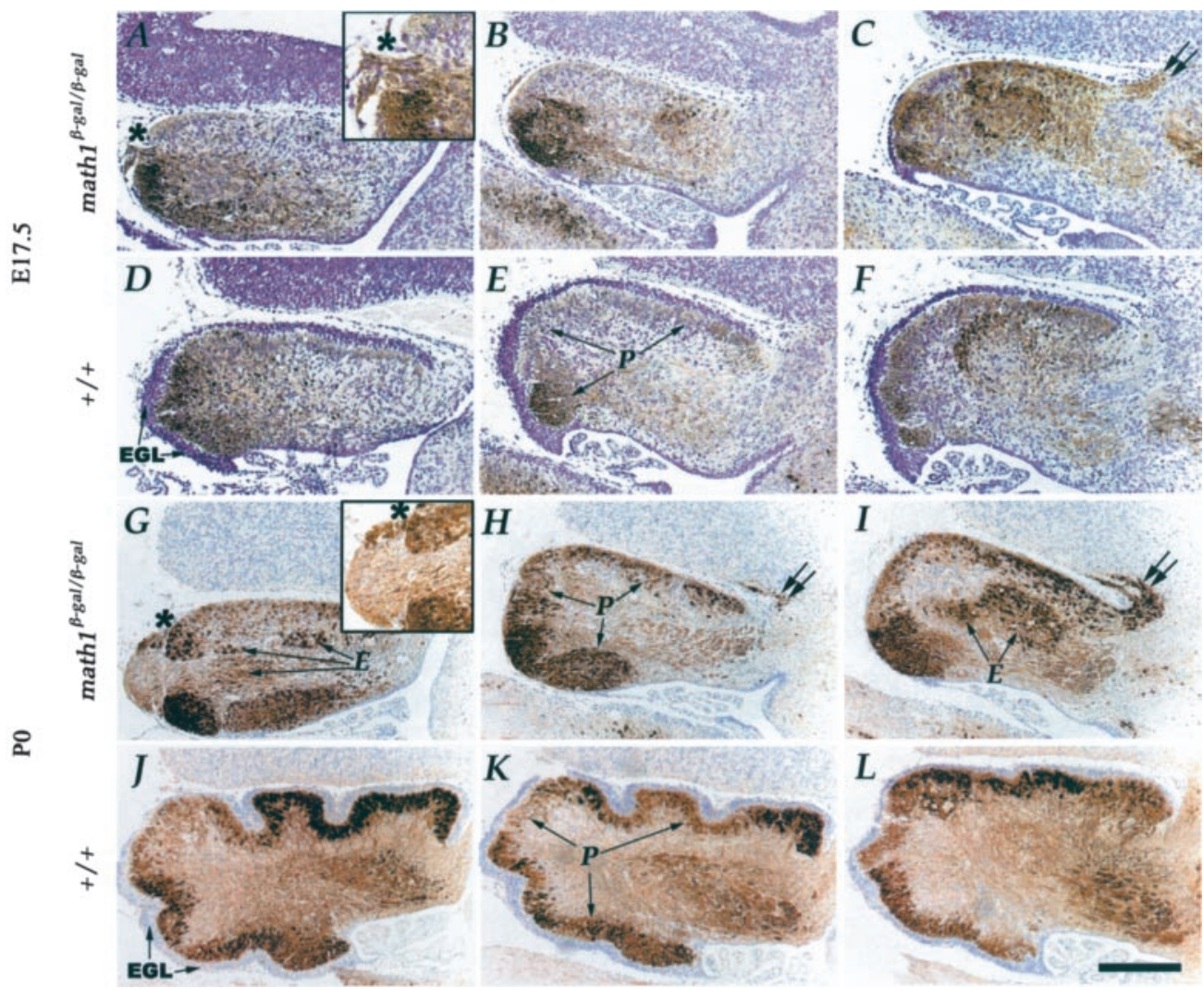

Table 1. Purkinje cell number in the math $^{\beta-G a l / \beta-G a l}$ and math $^{+/+}$cerebellum

\begin{tabular}{|c|c|c|c|c|}
\hline \multirow[b]{2}{*}{ Genotype } & \multirow{2}{*}{$\begin{array}{l}\text { Purkinje cell } \\
\text { number }^{a}\end{array}$} & \multicolumn{3}{|c|}{ Number and regional distribution of ectopic Purkinje cells ${ }^{b}$} \\
\hline & & IC & $\mathrm{SCB}$ & ICB \\
\hline math $1^{\beta-G a l / \beta-G a l}$ & $54,859 \pm 5192$ & $3798(6.9 \%)^{c}$ & $563(1.0 \%)$ & $10,933(20 \%)$ \\
\hline math $1^{+/+}$ & $54,848 \pm 4539$ & None & None & $1145(2.1 \%)$ \\
\hline
\end{tabular}

${ }^{a}$ Mean number of Purkinje cells per half cerebellum calculated for $n=3 \pm$ SD. Numbers determined as described in Materials and Methods.

${ }^{b}$ Mean number of ectopic Purkinje cells within the inferior colliculus (IC), supracerebellar region (SCB), and intracerebellar region (ICB) calculated for $n=3$ mice.

${ }^{c}$ In parentheses are percentages of total number of Purkinje cells.

cells in the $\mathrm{P} 0$ math $^{\beta-G a l / \beta-G a l}$ cerebellum, there were still numerous Purkinje cells deep to the PCP. This Purkinje cell ectopia was most prominent at the midline (Fig. $1 G$ ) and mid-hemisphere (Fig. 1I), and at both of these regions the PCP in the anterior cerebellum was not as well defined as in the posterior cerebellum (Fig. 1G,I). In addition, the extracerebellar ectopia in the mesencephalon (Fig. $1 I$ ) and the supracerebellar ectopia at the dorsal midline (Fig. $1 G$, inset) were more pronounced than at E17.5.

\section{Quantitative analysis of math1 null cerebellum}

To determine whether the absence of the EGL has an effect on Purkinje cell number, we counted Purkinje cells in P0 math $1^{\beta-G a l \beta-G a l}$ and math $1^{+/+}$cerebella. We determined the total number of Purkinje cells for one-half of the cerebellum (see Materials and Methods). We found no significant difference in the total number of Purkinje cells between the two genotypes (unpaired $t$ test; $p>0.1$ ) (Table 1). We also calculated the percentage of ectopic Purkinje cells and found that $28 \%$ of the total Purkinje cell population is in ectopic positions in the math $^{\beta-G a l / \beta-G a l}$ cerebellum, and only $2 \%$ is found in ectopic positions in the wild-type cerebellum (Table 1). Of the $28 \%$ ectopic Purkinje cells in the math $1^{\beta-G a l / \beta-G a l}$ cerebellum, $7 \%$ were located within the inferior colliculus, $1 \%$ were located at the dorsal midline in a supracerebellar position, and the majority, 20\%, were found deep to the PCP in an intracerebellar position (Table 1). The $2 \%$ of ectopic Purkinje cells in the wild-type cerebellum appeared to still be in the migratory phase of development, with their cell bodies oriented toward the PCP. However, this was not the case in the mutant cerebellum where the majority of ectopic Purkinje cell bodies had no consistent directionality, and in many cases were oriented away from the PCP.

\section{Birth-dating analysis of ectopic Purkinje cells}

In the math $1^{\beta-G a l / \beta-G a l}$ cerebellum, the anterior PCP was not as well defined as the posterior PCP. During normal Purkinje cell development, it is the latest born population of Purkinje cells, E13.0 in the mouse, that are destined for the anterior lobe of the cerebellum (Altman and Bayer, 1997). To determine whether the ectopic Purkinje cells within the math ${ }^{\beta G a l / \beta-G a l}$ cerebellum represent the latest born population, birth-dating analysis was performed using BrdU. Timed pregnant females were injected with BrdU at either the start of Purkinje cell genesis (E11 and E11.5) or the final stage of Purkinje cell genesis (E12.5 and E13.0), and their offspring were examined at $\mathrm{P} 0$ for Calbindin and BrdU 

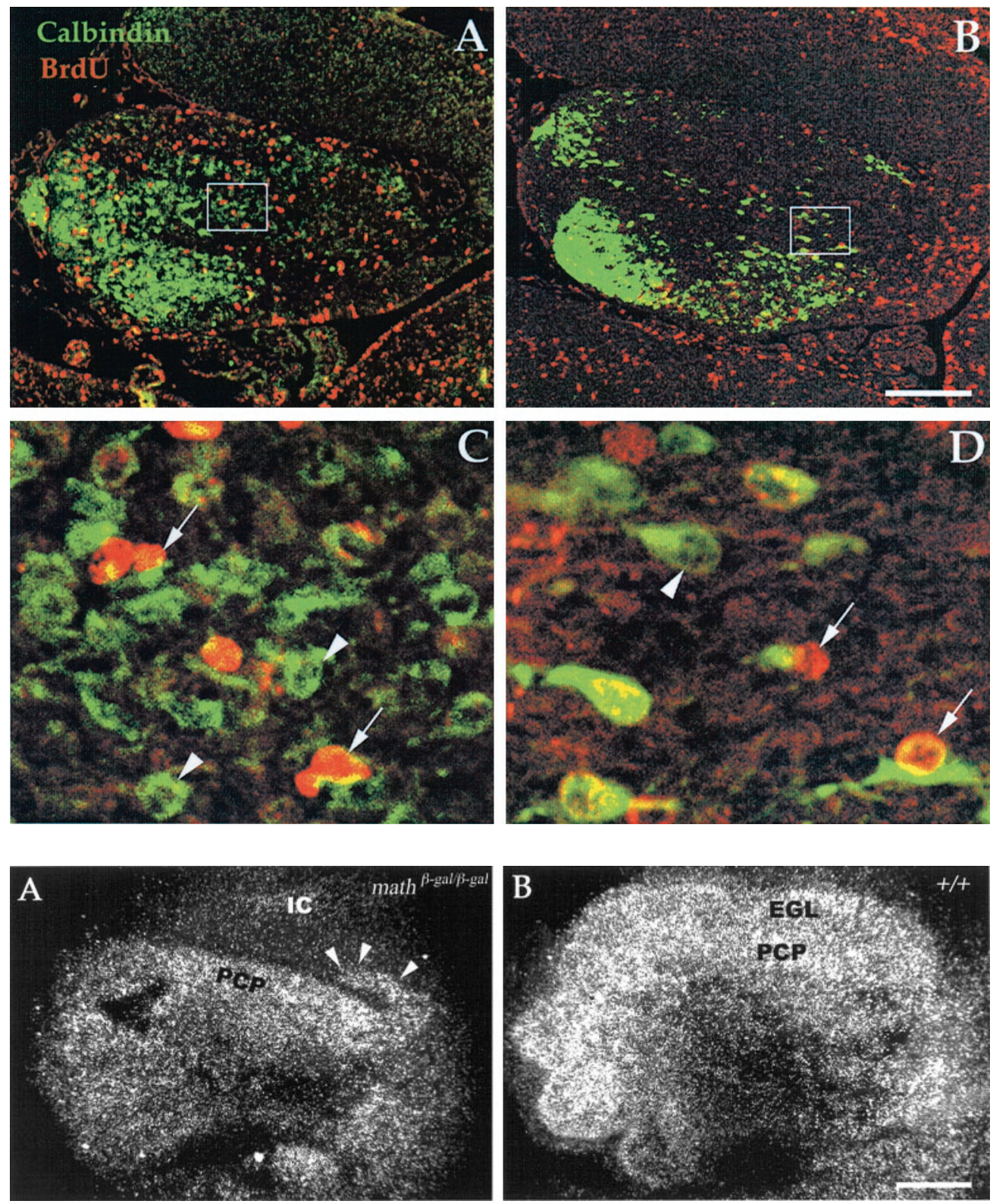

Figure 2. Ectopic Purkinje cells in the math $1^{\beta-G a l / \beta-G a l}$ cerebellum are composed of cohorts born at both early and late time points. $A-D$, Confocal images of $\mathrm{P} 0 \mathrm{math}^{\beta-G a l / \beta-G a l}$ cerebella that are double immunolabeled for the Purkinje cell marker Calbindin and BrdU. A, C, Pregnant dams were injected with BrdU at E11 and 11.5 and killed at P0 for immunocytochemistry. $B, D$, Pregnant dams were injected with BrdU at E12.5 and 13 and killed at P0 for immunocytochemistry. $C, D$, Two regions of ectopic Purkinje cells are shown in greater detail to demonstrate doublelabeled cells (arrows). Arrowheads point to single-labeled Calbindin-positive Purkinje cells. Scale bar (shown in $B$ ): $A, B, 200 \mu \mathrm{m} ; C, D, 25 \mu \mathrm{m}$.

Figure 3. Unc $5 \mathrm{~h} 3$ is expressed in all math $1^{\beta-\text { Gal } / \beta \text {-Gal }}$ Purkinje cells. Sagittal view of P0 math $1^{\beta-G a l / \beta \text {-Gal }}(A)$ and math $1^{+/+}(B)$ cerebella probed with antisense Unc5h3. In the math $1^{+/+}$cerebellum $(B), U n c 5 h 3$ is expressed in the cells of the external germinal layer $(E G L)$ and Purkinje cell plate $(P C P)$. In the math $1^{\beta-G a l / \beta-G a l}$ cerebellum $(A)$, Unc5h3 is expressed in the PCP and in ectopic Purkinje cells (arrowheads) in the inferior colliculus $(I C)$. Scale bar (shown in $B$ for $A$ and $B$ ): $200 \mu \mathrm{m}$. immunoreactivity. In the mutant cerebellum there were many double-labeled ectopic Purkinje cells that were born at both early (Fig. 2A,C) and later (Fig. 2B,D) time points. The presence of early-generated Purkinje cells in ectopic positions in the math $1^{\beta-G a l / \beta-G a l}$ cerebellum indicates that the time of Purkinje cell neurogenesis is not the sole factor in determining their successful migration.

\section{Unc5h3 signaling in the math1 null cerebellum}

The migration of Purkinje cells into the inferior colliculus in the math $1^{\beta-G a l / \beta-G a l}$ brain is reminiscent of the Purkinje cell ectopia found in the Unc5h3 mutant brain (Przyborski et al., 1998). Unc5h3 is expressed in cerebellar granule and Purkinje cells and is necessary for the establishment of the cerebellar territory (Ackerman and Knowles, 1998; Przyborski et al., 1998). In the Unc5h3 null-mutant mouse, both neuronal types migrate beyond the cerebellar boundary into the inferior colliculus (Przyborski et al., 1998). To determine whether the extracerebellar ectopia in the $m a t h 1^{\beta-G a l / \beta-G a l}$ cerebellum is caused by altered Unc5h3 ex- pression, we examined Unc5h3 mRNA expression at P0 by in situ hybridization. In the wild-type cerebellum, Unc $5 h 3$ was expressed in the cells of the EGL and the Purkinje cell population (Fig. 3B). In the math $^{\beta-G a l / \beta \text {-Gal }}$ cerebellum, all Purkinje cells, including the ectopic population in the inferior colliculus, also showed high levels of transcript (Fig. 3A), indicating that Unc5h3 expression does not appear to be affected. As found in the chimera analysis of the Unc5h3 null cerebellum (Goldowitz et al., 2000), this finding would indicate that in Purkinje cells, Unc5h3 does not function in setting the rostral cerebellar boundary.

\section{Reelin signaling in the math1 null cerebellum}

Reelin signaling from the EGL is thought to be a critical factor in the migration of Purkinje cells (Miyata et al., 1997; Curran and D'Arcangelo, 1998; D'Arcangelo and Curran, 1998; Rice and Curran, 1999). In the absence of Reelin, in the $r / / r l$ mouse, only $5 \%$ of the Purkinje cells migrate successfully (Heckroth et al., 1989). However, in the absence of the EGL in the math $1^{\beta-G a l / \beta-G a l}$ cerebellum, we found that $72 \%$ of the Purkinje cells migrate 
Figure 4. Comparison of Purkinje cell placement in the math ${ }^{\beta-G a l / \beta-G a l}$ and $r l / r l$ cerebellum. Sagittal view of the P0 math $1^{\beta-G a l / \beta-\text { Gal }}$ $(A)$ and $r l / r l(B)$ cerebellum immunostained for the Purkinje cell marker Calbindin and counterstained with cresyl violet. In the math $1^{\beta-\text { Gal } / \beta \text {-Gal }}$ cerebellum $(A)$, most of the Purkinje cells are located at the Purkinje cell plate $(P C P)$. In the $r l / r l$ cerebellum $(B)$, most of the Purkinje cells are located deep to the Purkinje cell plate. The dashed line is $100 \mu \mathrm{m}$ interior to the surface of the cerebellum in $A$ and $100 \mu \mathrm{m}$ interior to the inner EGL in $B$. Scale bar (shown in $B$ for $A$ and $B$ ): $200 \mu \mathrm{m}$.
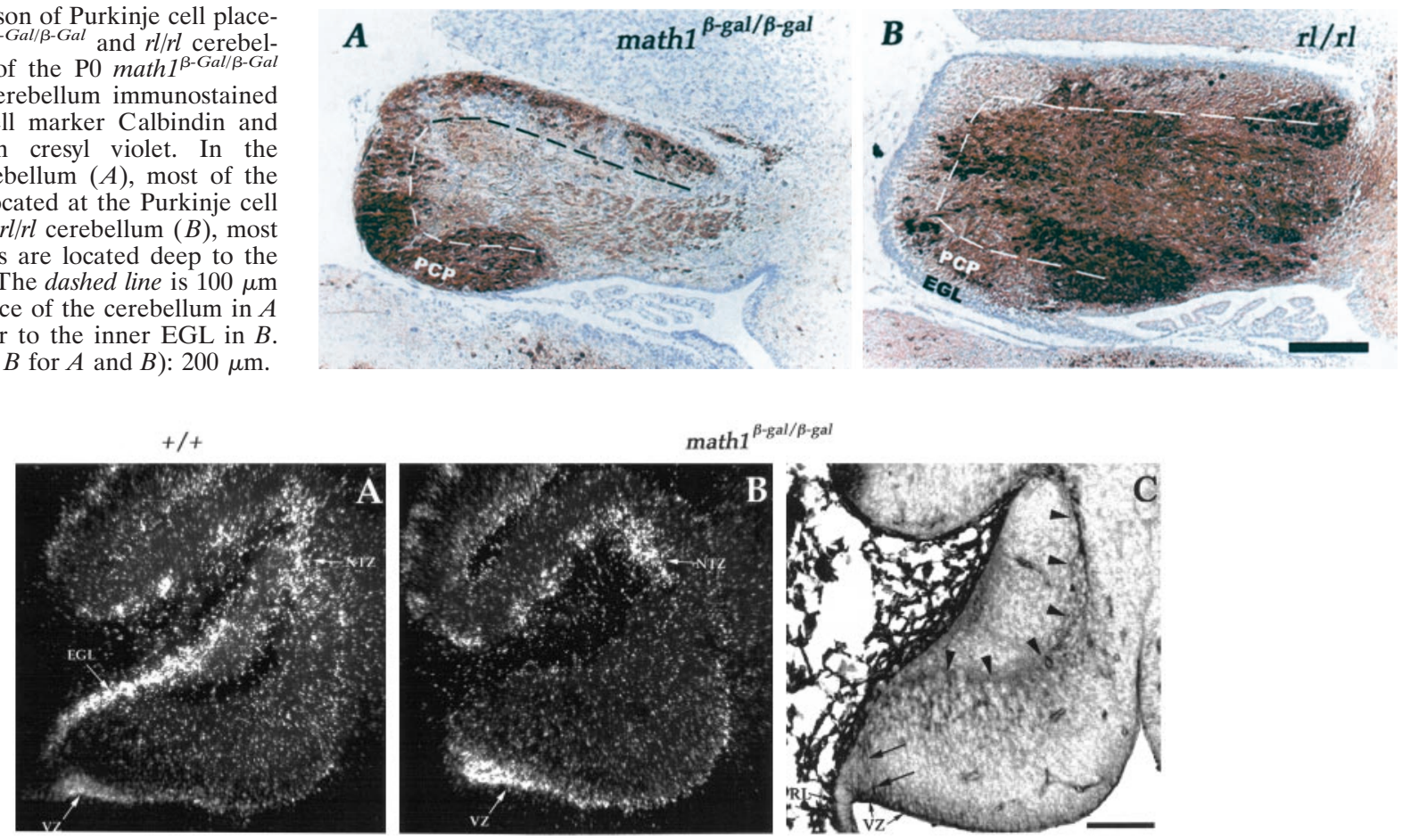

math1 $1^{\beta-g a l / \beta-g a l}$

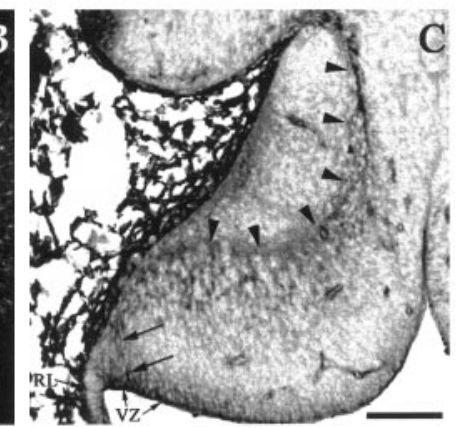

Figure 5. Reelin expression in the math $1^{\beta-G a l / \beta-G a l}$ cerebellum. Sagittal views of a E13.5 math $1^{+/+}(A)$ and $m a t h 1^{\beta-G a l / \beta \text {-Gal }}(B)$ cerebellum probed with antisense Reelin and a math $1^{\beta-G a l / \beta-G a l}(C)$ cerebellum immunostained for Reelin. In the math $1^{+/+}$cerebellum $(A)$, Reelin transcript is detected in the external germinal layer $(E G L)$, the nuclear transitory zone (NTZ), and the ventricular zone (VZ). In the math ${ }^{\beta-\text {-Gal } / \beta \text {-Gal }}$ cerebellum $(B)$, Reelin mRNA is only present in the NTZ and VZ. In a lateral section from the math $1^{\beta-G a l / \beta \text {-Gal }}$ cerebellum $(C)$, Reelin-immunopositive cells (arrows) are seen migrating away from the region of the VZ closest to the rhombic lip $(R L)$ and throughout the NTZ (arrowheads). Scale bar (shown in $C$ for $A-C$ ): $150 \mu$ m.

successfully to the PCP. This difference in the successful migration of Purkinje cells was obvious when we compared the positioning of Purkinje cells in the $\mathrm{P} 0 \mathrm{math}^{\beta-G a l / \beta-G a l}$ and $r l / r l$ cerebella (Fig. 4, compare $A, B$ ). On the basis of these observations, it was critical to examine other sources of Reelin expression in the math ${ }^{\beta-G a l / \beta-G a l}$ cerebellum. By in situ hybridization, we looked at Reelin mRNA expression at E13.5 in wild-type and math $1^{\beta-G a l / \beta-G a l}$ cerebella. In the wild-type cerebellum, Reelin transcripts were detected in the EGL, NTZ, and VZ (Fig. $5 A$ ). In the math $1^{\beta-G a l / \beta-G a l}$ cerebellum, there was no signal corresponding to where the EGL would have been located; however, Reelin transcripts were detected in the NTZ and the VZ (Fig. 5B). To confirm this, we also looked at Reelin protein expression by immunohistochemistry. At E13.5, in the math1 ${ }^{\beta-G a l / \beta-G a l}$ cerebellum, Reelin immunopositivity was observed in the NTZ and by a population of cells migrating away from the region of the $\mathrm{VZ}$ adjacent to the rhombic lip (Fig. 5C). This latter population of immunopositive cells was not likely Purkinje cells because they did not express Purkinje cell markers Disabled-1 or Calbindin. However, their route of migration corresponds to the path taken by cells that colonize the nuclear transitory zone, indicating that these cells may be the future cerebellar nuclear neurons (Altman and Bayer, 1997). We saw this same pattern of expression in the wild-type cerebellum, indicating that the only disruption in Reelin expression in the math $1^{\beta-G a l / \beta-G a l}$ cerebellum is the absence of signal from the EGL. This finding demonstrates that Reelin signaling from sources other than the EGL is adequate for the successful migration of the majority of Purkinje cells.

\section{Disabled-1 signaling in the math1 null cerebellum}

To further assess the Reelin signaling pathway, we investigated the intracellular protein Disabled-1, which functions downstream of Reelin (Howell et al., 1997; Sheldon et al., 1997). In the absence of Reelin, as demonstrated in the $r l / r l$ mouse, there are increased levels of Disabled-1 (Rice et al., 1998). We sought to examine the expression of Disabled-1 in the math $1^{\beta-G a l / \beta-G a l}$ cerebellum to determine whether Disabled-1 was altered in ectopic Purkinje cells. Our prediction was that there would be increased levels of Disabled-1 in the ectopic Purkinje cells because they did not receive an adequate Reelin signal. We compared Disabled-1 expression in math $^{\beta-G a l / \beta-G a l}$ and math $^{+/+}$ cerebella by immunohistochemistry (Fig. $6 C, D$ ). At all ages examined before P0 there was no obvious difference in Disabled-1 immunoreactivity between the math $1^{\beta-G a l / \beta-G a l}$ and $m a t h 1^{+/+}$ cerebellum (Fig. 6A,B). At $\mathrm{P} 0$, we found that there was an increase in Disabled-1 immunoreactivity in the math $1^{\beta-G a l / \beta-G a l}$ cerebellum (Fig. 6C). Interestingly, the increased immunoreactivity was not limited to the ectopic Purkinje cells but was also seen in Purkinje cells that had migrated successfully.

\section{DISCUSSION}

The math1 null-mutant mouse provides a fascinating model system to examine the importance of the EGL in cerebellar morphogenesis and Purkinje cell migration and positioning. It has allowed us to critically examine the influence of Reelin signaling from the EGL in Purkinje cell migration and to validate the role of the EGL in establishing the rostral cerebellar boundary through the expression of Unc5h3.

The absence of foliation in the math1 null mouse demonstrates the critical role of prenatal granule cell precursors as the motive force in this process. Previous studies in which the EGL was disrupted during the prenatal period, using irradiation or chemical insult, found that foliation is EGL dependent, whereas initial fissure formation occurs independently of the EGL (Chen and 

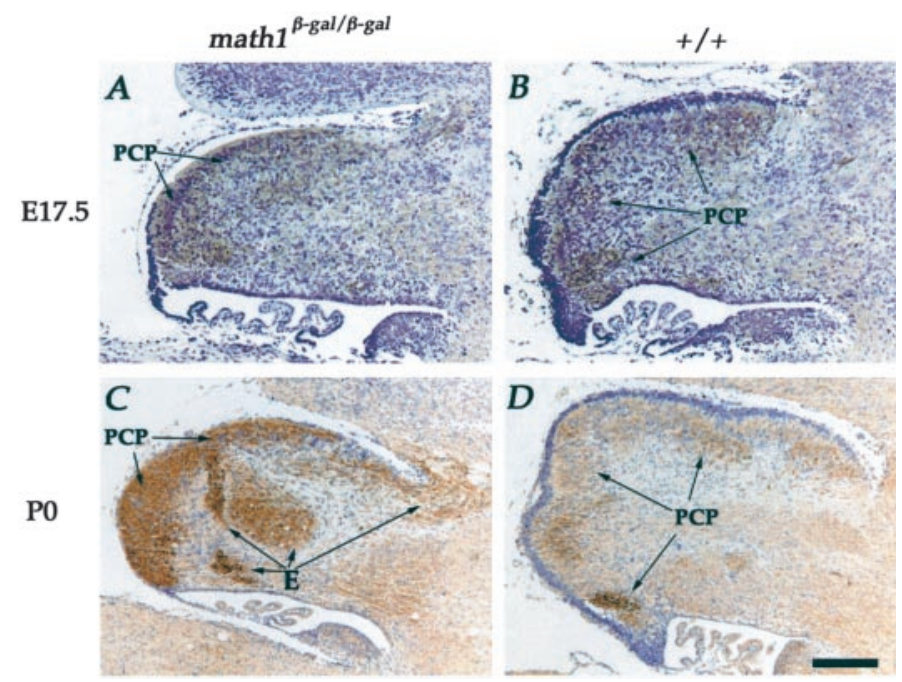

Figure 6. Disabled-1 is increased in P0 math $1^{\beta-G a l / \beta-G a l}$ Purkinje cells. Sagittal views of the E17.5 math $1^{\beta-G a l / \beta-G a l}(A)$ and math $^{+/+}(B)$ cerebellum and the P0 math1 $1^{\beta-G a l / \beta-G a l}(C)$ and math $^{+/+}(D)$ cerebellum immunostained for Disabled-1. Sections were counterstained with cresyl violet to highlight the EGL and its relative position to Disabled-l-positive Purkinje cells. At E17.5, there is no obvious difference in Disabled-1 immunoreactivity between the math $1^{\beta-\text { Gal } \beta \text {-Gal }}(A)$ and math $1^{++}(B)$ cerebellum. At P0, however, there is increased immunoreactivity in math $1^{\beta-G a l / \beta \text {-Gal }}$ Purkinje cells $(C)$, as compared with the wild-type cerebellum $(D)$. Note that in the math $1^{\beta-G a l / \beta-\text { Gal }}$ cerebellum $(C)$, Disabled-1 is increased in both the ectopic Purkinje cells $(E)$ and in the cells of the Purkinje cell plate $(P C P)$. Scale bar (shown in $D$ for $A-D$ ): $200 \mu \mathrm{m}$.

Hillman, 1986, 1988; Doughty et al., 1998). These studies, however, were limited to specific times during prenatal EGL development, resulting in only partial disruptions of the EGL because of the regenerative capacity of granule cell precursors. The results from the math 1 null mutant, where the EGL is completely eliminated throughout embryonic development, confirm these authors' interpretation of the role of the EGL in formatting cerebellar foliation.

The principal rationale behind these current studies was to better define the relationship between the developing EGL and Purkinje cell migration. We have identified three distinct ectopic populations of math1 null Purkinje cells that are obvious as early as E17.5. A first population of ectopic Purkinje cells (representing only $1 \%$ of the total Purkinje cell number) is found in a supracerebellar position at the dorsal midline in $\sim 50 \%$ of mutant brains. This abnormality is most likely related to the absence of the EGL at the dorsomedial aspect of the cerebellum, where final fusion of the cerebellar primordia occurs. In the math1 null, we found that this fusion event does not occur, leaving a crevice at the dorsal midline that is visible during gross dissection of the cerebellum. This crevice separates two large populations of Purkinje cells that would normally become aligned as the cerebellar primordia expand and fuse. Instead, in the mutant, Purkinje cells remain concentrated under, and lateral to, the crevice. It is speculated that some variable feature of the mutant cerebellum (such as a disrupted pial lining) permits this unusual accumulation of Purkinje cells, in their migratory phase of development, to stream outside the cerebellum.

A second population of ectopic Purkinje cells (representing $\sim 7 \%$ of the total Purkinje cell number) was always found in the inferior colliculus. Mutations in the Netrin-like receptor Unc5h3, which functions in establishing cerebellar boundaries, also results in a similar phenotype (Ackerman and Knowles, 1998; Przyborski et al., 1998). Unc5h3 is expressed in Purkinje cells and granule cell precursors in the cerebellum. Our finding that there is no disruption in Unc5h3 expression in ectopic Purkinje cells implies that Unc5h3 expression in these cells does not inhibit their migration outside the cerebellum. This is in agreement with the result of $U n c 5 h 3$ null chimera (Unc5h3/Unc5h3 $\leftrightarrow+/+$ ) studies, where both $+/+$ and Unc5h3/Unc5h3 Purkinje cells ignore the anterior cerebellar boundary (Goldowitz et al., 2000). In chimeras, the only ectopic granule cells were genotypically unc $5 \mathrm{~h} 3 /$ unc 5 h3, indicating that wild-type granule cell precursors are the effective cells in reading the Unc5h3 mediated signal (Goldowitz et al., 2000). Given that these cells do not exist in the math1 null, our current findings support the role of EGL granule cell precursors in establishing the anterior cerebellar boundary through the expression of Unc5h3.

The third ectopic population of Purkinje cells is found deep to the PCP. This population is by far the most numerous, representing $\sim 20 \%$ of the total Purkinje cell number. This ectopia is most prominent at the midline and mid-hemisphere and is consistently seen among mutants. It is likely that $\sim 2 \%$ of these cells would ultimately reach the PCP as seen in $+/+$ control brains. Thus, $18 \%$ of the Purkinje cells appear to be dependent on the EGL for proper migration.

An alternate interpretation of these results is that the ectopic Purkinje cell population is developmentally delayed and would ultimately migrate to the PCP if the math1 null mouse had survived into the postnatal period. This is an unlikely possibility because some ectopic Purkinje cells are from the earliest born cohorts (at E11.0), which would be expected to have migrated the farthest. Furthermore, all mutant animals show exuberant extracerebellar migration into the mesencephalon, and $\sim 50 \%$ show supracerebellar migration at the midline. Finally, our analysis of math $1^{\beta-G a l / \beta-G a l} \leftrightarrow+/+$ chimeras, which survive as late as P21, still have mutant Purkinje cells in ectopic positions (P. Jensen and D. Goldowitz, unpublished results). These findings contraindicate any delay in the migratory process.

Thus, the most likely interpretation is that the EGL is necessary for the migration of these ectopic Purkinje cells in the math1 null cerebellum, and the most likely feature of the EGL that is critical to successful migration is the signaling molecule Reelin. The fact that ectopic math1 null Purkinje cells demonstrate increased levels of Disabled-1, which functions downstream of Reelin and is increased in the absence of Reelin signal (Rice et al., 1998; Trommsdorff et al., 1999), suggests that these cells are not receiving adequate Reelin signal. It is interesting that there is also an increase in Disabled-1 expression in normally placed Purkinje cells in the P0 math $1^{\beta-G a l / \beta-G a l}$ cerebellum. This increase in Disabled-1 is not seen before PO. These findings suggest that either Reelin signaling from the EGL may have a second function in addition to guiding the migration of Purkinje cells, or that a "yet-to-be-identified" signaling mechanism is responsible for the accumulation of Disabled-1.

In the absence of the Reelin signal in the reeler mouse, $95 \%$ of the Purkinje cells are ectopic (Heckroth et al., 1989). Our finding that only approximately one-fifth of the Purkinje cells are dependent on the EGL for successful migration has significant ramifications with regard to how we view Reelin signaling in the cerebellum. Our results indicate that in the absence of the EGL there is another signaling mechanism to guide the migration of Purkinje cells. All current evidence points to Reelin as this signaling mechanism. That is, there is no alternative or compensatory mechanism to promote the migration of Purkinje cells in 
the complete absence of Reelin signal as evident in the reeler mutant and the VLDLR and ApoER/2 double knock-out mice (Rice et al., 1998; Trommsdorff et al., 1999). Thus, on the basis of our current understanding of Reelin signaling, another source of Reelin (other than the EGL) provides a key signal for Purkinje cell migration. It has typically been assumed that Reelin signaling from the EGL is essential for Purkinje cell migration, although it has been well established that the cells of the NTZ and VZ also express Reelin (D'Arcangelo et al., 1995; Miyata et al., 1996; Schiffmann et al., 1997; Rice et al., 1998; our current findings). Considering the temporo-spatial relationships during cerebellar development, the cells of the NTZ and the VZ are likely candidates for Reelin signaling during early Purkinje cell migration. During the earliest phase of Purkinje cell migration, E13, the EGL is just beginning to form. At this time, only those Purkinje cells arising from the most lateral neuroepithelium are in proximity to the forming EGL. Most of the newly born Purkinje cells are more medially placed. These cells are most likely influenced by the cells of the NTZ, which are the earliest generated neurons of the cerebellum (E10) and migrate in a circuitous manner in the superficial cerebellar primordia just above the migrating Purkinje cells (Altman and Bayer, 1997). Their temporal and spatial juxtaposition to the migrating Purkinje cells make them a prime candidate as the primary source of Reelin during early Purkinje cell migration.

The specific features of Purkinje cells that are EGL responsive are unknown. Two obvious factors that could determine responsiveness are the time and place of birth. The EGL does not begin to form until E13. Thus, it might be expected that the latest born Purkinje cells (i.e., those born at E12.5-13) are targets of signals arising from the EGL. However, we find that this is not the case, because those Purkinje cells that are ectopic are born throughout the entire neurogenetic period. Therefore, some other factor, such as the site of genesis within the neuroepithelium, or the course and distance of migration to their final position, may play an important role in determining the effective source of Reelin signal.

Our present findings have defined at least two sources of Reelin involved in the successful migration of Purkinje cells. The baseline phenotype when the Reelin signal is completely absent (as in the reeler mutant mouse) is the ectopic positioning of $95 \%$ of all Purkinje cells (Heckroth et al., 1989). In the math1 null cerebellum, where only the EGL source of Reelin has been removed, $\sim 20 \%$ of all Purkinje cells remain ectopic, deep to the PCP. These ectopic Purkinje cells would be, by definition, the EGLresponsive population. The $70+\%$ that successfully migrate in the math1 null cerebellum are driven by Reelin from another source. This additional source, analogous to the Cajal-Retzius cells of cortex, is most likely the first born neurons of the cerebellum, the nuclear neurons. This was a surprising result in that another effective source of Reelin was identified, and it had homology to Reelin signaling in cortex. The fact that one population of cells (the Purkinje cells) are under the influence of at least two different sources of Reelin indicates the complexity and richness of the processes that guide migration in the CNS.

\section{REFERENCES}

Abercrombie M (1946) Estimation of nuclear population from microtome sections. Anat Rec 94:239-247.

Ackerman SL, Knowles BB (1998) Cloning and mapping of the UNC5C gene to human chromosome 4q21-q23. Genomics 52:205-208.

Ackerman SL, Kozak LP, Przyborski SA, Rund LA, Boyer BB, Knowles BB (1997) The mouse rostral cerebellar malformation gene encodes an UNC-5-like protein. Nature 386:838-842.

Akazawa C, Ishibashi M, Shimizu C, Nakanishi S, Kageyama R (1995) A mammalian helix-loop-helix factor structurally related to the product of Drosophila proneural gene atonal is a positive transcriptional regulator expressed in the developing nervous system. J Biol Chem 270:8730-8738.

Altman J, Bayer SA (1997) Development of the cerebellar system: in relation to its evolution, structure, and functions. Boca Raton, FL: CRC.

Ben-Arie N, Bellen HJ, Armstrong DL, McCall AE, Gordadze PR, Guo Q, Matzuk MM, Zoghbi HY (1997) Math1 is essential for genesis of cerebellar granule neurons. Nature 390:169-172.

Bermingham NA, Hassan BA, Price SD, Vollrath MA, Ben-Arie N, Eatock RA, Bellen HJ, Lysakowski A, Zoghbi HY (1999) Math1: an essential gene for the generation of inner ear hair cells. Science 284:1837-1841.

Chen S, Hillman DE (1986) Selective ablation of neurons by methylazoxymethanol during pre- and postnatal brain development. Exp Neurol 94:103-119.

Chen S, Hillman DE (1988) Developmental factors related to abnormal cerebellar foliation induced by methylazoxymethanol acetate (MAM). Brain Res 468:201-212.

Curran T, D'Arcangelo G (1998) Role of reelin in the control of brain development. Brain Res Brain Res Rev 26:285-294.

D'Arcangelo G, Curran T (1998) Reeler: new tales on an old mutant mouse. BioEssays 20:235-244.

D'Arcangelo G, Miao GG, Chen SC, Soares HD, Morgan JI, Curran T (1995) A protein related to extracellular matrix proteins deleted in the mouse mutant reeler. Nature 374:719-723.

D'Arcangelo G, Miao GG, Curran T (1996) Detection of the reelin breakpoint in reeler mice. Brain Res Mol Brain Res 39:234-236.

Doughty ML, Delhaye-Bouchaud N, Mariani J (1998) Quantitative analysis of cerebellar lobulation in normal and agranular rats. J Comp Neurol 399:306-320.

Goldowitz D, Hamre KM, Przyborski SA, Ackerman SL (2000) Granule cells and cerebellar boundaries: analysis of Unc5h3 mutant chimeras. J Neurosci 20:4129-4137.

Heckroth JA, Goldowitz D, Eisenman LM (1989) Purkinje cell reduction in the reeler mutant mouse: a quantitative immunohistochemical study. J Comp Neurol 279:546-555.

Helms AW, Johnson JE (1998) Progenitors of dorsal commissural interneurons are defined by MATH1 expression. Development 125:919-928.

Howell BW, Hawkes R, Soriano P, Cooper JA (1997) Neuronal position in the developing brain is regulated by mouse disabled-1. Nature 389:733-737.

Jiao Y, Sun Z, Lee T, Fusco FR, Kimble TD, Meade CA, Cuthbertson S, Reiner A (1999) A simple and sensitive antigen retrieval method for free-floating and slide-mounted tissue sections. J Neurosci Methods 93:149-162.

Miale IL, Sidman RL (1961) An autoradiographic analysis of histogenesis in the mouse cerebellum. Exp Neurol 4:277-296.

Miyata T, Nakajima K, Aruga J, Takahashi S, Ikenaka K, Mikoshiba K, Ogawa M (1996) Distribution of a reeler gene-related antigen in the developing cerebellum: an immunohistochemical study with an allogeneic antibody CR-50 on normal and reeler mice. J Comp Neurol 372:215-228.

Miyata T, Nakajima K, Mikoshiba K, Ogawa M (1997) Regulation of Purkinje cell alignment by reelin as revealed with CR-50 antibody. J Neurosci 17:3599-3609.

Ohshima T, Ward JM, Huh CG, Longenecker G, Veeranna, Pant HC, Brady RO, Martin LJ, Kulkarni AB (1996) Targeted disruption of the cyclin-dependent kinase 5 gene results in abnormal corticogenesis, neuronal pathology and perinatal death. Proc Natl Acad Sci USA 93:11173-11178.

Przyborski SA, Knowles BB, Ackerman SL (1998) Embryonic phenotype of Unc5h3 mutant mice suggests chemorepulsion during the formation of the rostral cerebellar boundary. Development 125:41-50.

Rice DS, Curran T (1999) Mutant mice with scrambled brains: understanding the signaling pathways that control cell positioning in the CNS. Genes Dev 13:2758-2773.

Rice DS, Sheldon M, D’Arcangelo G, Nakajima K, Goldowitz D, Curran $\mathrm{T}$ (1998) Disabled-1 acts downstream of Reelin in a signaling pathway that controls laminar organization in the mammalian brain. Development 125:3719-3729.

Schiffmann SN, Bernier B, Goffinet AM (1997) Reelin mRNA expression during mouse brain development. Eur J Neurosci 9:1055-1071.

Sheldon M, Rice DS, D’Arcangelo G, Yoneshima H, Nakajima K, Mikoshiba K, Howell BW, Cooper JA, Goldowitz D, Curran T (1997) Scrambler and yotari disrupt the disabled gene and produce a reelerlike phenotype in mice. Nature 389:730-733.

Trommsdorff M, Gotthardt M, Hiesberger T, Shelton J, Stockinger W, Nimpf J, Hammer RE, Richardson JA, Her J (1999) Reeler/Disabledlike disruption of neuronal migration in knockout mice lacking the VLDL receptor and ApoE receptor 2. Cell 97:689-701.

Yuasa S, Kawamura K, Ono K, Yamakuni T, Takahashi Y (1991) Development and migration of Purkinje cells in the mouse cerebellar primordium. Anat Embryol 184:195-212. 